\title{
Drug Abuse Monitoring: Which Pharmacoepidemiological Resources at the European Level?
}

\author{
Maryse Lapeyre-Mestre ${ }^{1}$ and Mathilde Dupui ${ }^{1}$ \\ CEIP-Addictovigilance de Toulouse, Service de Pharmacologie Médicale et Clinique, CHU de Toulouse, Toulouse, France \\ Inserm U1027, Université Paul Sabatier - Toulouse 3, Toulouse, France
}

Text received September $25^{\text {th }}, 2014$; accepted October $9^{\text {th }}, 2014$

\section{Keywords:}

pharmacology; pharmacoepidemiology; databases; misuse; abuse; dependence; drug abuse monitoring; psychotropic drugs; pregabalin

\begin{abstract}
Monitoring the potential for abuse and dependence of psychoactive substances falls within the scope of international conventions on narcotic drugs. At the European level, this monitoring is based on activities controlled by the European Monitoring Centre for Drugs and Drug Addiction (EMCDDA) for substance abuse in general and by the European Medicines Agency (EMA) for marketed drugs, in the context of pharmacovigilance. If France has set up in the early 1990s an original system to assess potential for abuse of psychoactive substances, with specific tools combining both the evaluation of the use of these substances (illicit substances or diverted drugs), and the consequences of that use in terms of morbidity and mortality, there is no equivalent in other European countries. Indeed, unlike the USA, who, for several decades, organized this type of surveillance, with a multisource approach (sentinel systems, databases, medical and administrative data, databases for seeking care in relation abuse), we have not found in other European countries integrated system for identifying a signal of drug abuse, or to assess the impact of measures for minimizing the risk of abuse. However, some recent examples show a growing concern about drug addiction, based on a pharmacoepidemiological approach using pharmacovigilance databases or medical administrative data. These examples illustrate the interest of these approaches in the field of drug of abuse.
\end{abstract}

Abbreviations: see end of article.

\section{Introduction}

In 2007, the number of deaths and complications related to drug abuse in the USA exceeded that of those related to illegal substances such as heroin or cocaine. ${ }^{[1]}$ This situation led the USA to strengthen both their drug abuse monitoring system, and secondly, to establish risk management plans to minimize diversion of prescription drugs. ${ }^{[2-5]}$ Several pharmacoepidemiological tools, including analysis of "doctor shopping" in prescription databases, data collection about substance use in specialized structures, identification of adverse events related to drug abuse in pharmacovigilance systems, or multi-source approach combining several data sources have been widely described in the literature. ${ }^{[6,7]}$ In the USA, the number of people abusing prescription drugs exceeds those who admit abusing cocaine, hallucinogens, inhalants and heroin. As an example, increased medical use of opioids in USA is directly correlated with increased abuse as well as subsequent morbidity and mortality. Actually, the level of use of opioid analgesics in North America is the highest in the world. ${ }^{[8]}$ According to the European Monitoring Centre for Drugs and Drug Addiction (EMCDDA), abuse of prescription drugs is also increasing in Europe, although literature on the extent of the phenomenon remains scarce, limiting the understanding of the problem at the European level. ${ }^{[9,10]}$ As highlighted in the recent review of 
Bramness et al., the share of research on substance abuse is particularly weak in Europe compared with the USA. ${ }^{[11]}$ The purpose of this article is to review the characteristics of pharmacoepidemiology data regarding abuse of marketed drugs available in Europe.

\section{Organization of control and monitoring of drugs with abuse potential}

Internationally, narcotics and psychotropic drugs are included in specific schedules related to international conventions established by the United Nations, namely the 1961' Single Convention on Narcotic Drugs, as amended by the 1972 Protocol, and the 1971' Convention on Psychotropic Substances. The objective of these conventions is to ensure adequate availability of narcotic drugs and psychotropic substances for medical and scientific purposes worldwide, while ensuring that such drugs are not diverted for illicit purposes. These conventions give the rules of the international monitoring of narcotic and psychotropic drugs production, prohibiting any use without prior authorization from national authorities. In essence, these international agreements limit exclusively possession and production of scheduled substances to "medical and scientific" use. These conventions also insure the availability of drugs (for example analgesic opioids and drugs for opiate maintenance treatments) for medical and scientific purposes (while preventing runoff on illicit market). The World Health Organization (WHO) is responsible for the evaluation of pharmacological properties and the potential for abuse of the substances within these international conventions. WHO relies on the skills of its Expert Committee on Drug Dependence, and has an advisory role on the international scheduling of certain substances. WHO also promotes drug safety monitoring (including narcotic and psychotropic drugs for medical use), under the coordination of the Uppsala Monitoring Centre (UMC) located in Sweden. This Collaborating Centre for Drug Monitoring is in charge of the promotion and coordination of drug safety activities from the national pharmacovigilance systems around the world. Information on adverse drug reactions recorded by national systems are transmitted to the UMC and registered in a common database, VigiBase ${ }^{\mathrm{TM}}$, accessible without any restrictions for members of the WHO Programme. Reports of drug abuse or misuse included in VigiBase ${ }^{\mathrm{TM}}$ are considered for the evaluation of the potential for abuse of some medications.

These international agreements apply at the state level and therefore concerned all European countries, but not at the level of the European Union. Actually, 2 different institutions are involved in the regulation of psychotropic or narcotic drugs in Europe: the EMCDDA, in charge of the surveillance of drugs and drug addiction, and the European Medicines Agency (EMA), responsible for the benefit-risk assessment of medicines for human (and veterinary) use.
Originally founded to fight against the use and trafficking of illicit drugs, the EMCDDA aims to provide information necessary to understand the phenomenon of drug abuse, including diversion of prescription drugs. ${ }^{[11]}$ EMCDDA presents information related to the status of psychotropic and narcotic drugs in the 28 Member States and Norway in the European Legal Database on Drugs (ELDD). ${ }^{[12]}$ This database includes drugs marketed in Europe, and their status as available through official sources (including national drug regulatory agencies). Each European state being sovereign for more strictly control drugs (for example by classifying a drug as a narcotic, restricting or tight control of prescription and / or delivery, or by limiting its accessibility), this database allows to compare national legislations.

The objectives of the EMCDDA were primarily focused on illicit substances recently spread throughout the European territory. Gradually, misuse and abuse of prescription drugs appears to be an increasing part of abuse phenomenon. The exchanges of information between the EMCDDA and EMA began in 1995 at the creation of the two institutions, but have evolved recently towards a more effective cooperation. The EMA is a key partner in the early warning system for new substances (EWS) and participates in the risk assessment of these substances. Cooperation between the EMCDDA and EMA takes place in the framework of Decision 2005/387/ JHA of the Council of the European Union on the information exchange, risk assessment and control of new psychoactive substances. According to this decision, "substances whose medical value is established and acknowledged... are not subject to control measures based on this decision. Regulatory and appropriate public health measures should be taken with regard to substances with established and recognized medical value that are being misused." Similarly, "... in addition to what is provided for under the pharmacovigilance systems as defined in Directives 2001/82 / EC and 2001/83 / EC, the exchange of information on psychoactive substances which are the subject of abuse or misuse should be increased and should ensure appropriate cooperation with the European medicines Agency."

The European pharmacovigilance database at the EMA EudraVigilance - and the EMCDDA database on new substances are used to allow the exchange of information. The two institutions have signed a new agreement in September 2012, strengthening cooperation and under which they agree to exchange the information they receive on drug abuse.

\section{Pharmacovigilance and addictovigilance}

In 2010, the European Parliament and the Council of the European Union launched the reform of the pharmacovigilance system with the adoption of the Directive 2010/84/UE and the EU regulation 1235/2010. The new law, implemented in July 2012, 
strengthens drug safety monitoring. This new law aims to increase transparency and communication within the European Union, summarized in three steps: extending the concept of adverse effects, expanding the reporting of these adverse effects and efforts to centralize these reports in a single database (EudraVigilance). Thus, the concept of adverse effect, defined as noxious and unintended response to a drug, now covers under the Directive, the "medication errors and (the) use inconsistent with the terms of marketing authorization, including the misuse and abuse of drugs". Patients are given the right to directly notify all suspected adverse reactions to the national health authority which then forward at EU level. Finally, the Directive requires to make public the EudraVigilance data within the European Union. EudraVigilance should be accessible to all persons concerned, that is to say, to member states, to EMA, to marketing authorization holders and should be also publicly accessible, while ensuring the personal data protection. In this context, EudraVigilance has been made available in 2012 on a dedicated website, ${ }^{[13]}$ which only provides information on drugs under centralized procedure. These new provisions are hoping a faster and more relevant information on the phenomenon of drug abuse in Europe.

\section{Abuse monitoring systems at the European level}

Data on a set of drug related indicators are collected at the national level, and reported to and collated by the EMCDDA and the United Nations Office on Drugs and Crime (UNODC). According to data from the literature, the specific monitoring systems of abuse are based on several sources of information: spontaneous reports from pharmacovigilance systems, morbid consequences of abuse (drug-related deaths or drug-related emergency visits, data from poison control centres), general population and / or specific population (youth, drug users) surveys, prescription databases to evaluate usage patterns in terms of doctor shopping. ${ }^{[5]}$ However, such an organization does not exist in Europe, with the exception of the provision of EudraVigilance, but to the best of our knowledge, this database has not been used to date to explore the issue of abuse.

Sources giving updated and complete data regarding the legal status and national scheduling and prescription and/or delivery rules of drugs with a potential for abuse are lacking at the European level, with the exception of the ELDD (but which has not been updated since 2008). The EU Directive 2001/83/EC gives a scheme to classify a medicinal product as subject to medical prescription or non-prescription. For prescription drugs, the Directive proposes three categories: renewable and non-renewable prescription, special medical prescription, restricted medical prescription. So, for one prescription drug, they should be as many ways to access to this drug as they are different European countries. Regarding these differences of access, this is very difficult to compare drug utilisation between countries, especially when information on the level of use are not easily accessible. Some national agencies (mostly from Scandinavian countries) give free access to drug consumption data, presented through different indicators including the number of defined daily doses (DDD). These data provide very detailed information on drug consumption, and should be used to assess trends of drug use, and to assess the impact of regulatory measures on drug use.

General population studies are regularly conducted at European level, and used by the EMCDDA, for monitoring risk behaviour in terms of substance abuse. These studies are the general population survey, the Health Behaviour in School Children (HBSC) study and the European School Survey Project on Alcohol and Drugs (ESPAD) study on populations of children and adolescents. However, when these studies explore the use of drugs, they refer to hypnotics and anxiolytics without ever naming the substances. ${ }^{[5]}$ Moreover, the "non-medical" use means access to these products without a prescription. Since self-medication is particularly common, this "non-medical" use is not very informative regarding the patterns of abuse or misuse. ${ }^{[14]}$

Finally, by contrast with the USA, there is no unique poison centres network in Europe, and data on drug-related deaths, information used by the EMCDDA as an indicator of problematic use, are not homogeneous across countries. In the literature, data on the drug-related deaths come mainly from Scandinavian countries.

\section{Available data sources related to drug abuse in Europe}

In 2012, Casati et al. ${ }^{[15]}$ conducted a systematic review of the literature on the misuse of medicines in the EU. Main topics included an assessment of the extent of the problem of medicine misuse and dependence for different types of medicines, a description of the populations that are particularly at risk of engaging in medicine misuse, and a characterization of patterns of misuse and factors related to misuse. This review focused on the misuse of analgesics, opioid substitution medicines and $\mathrm{Z}$ drugs (excluding benzodiazepines and anabolic steroids which need a specific review), with a generic definition of misuse including all types of drug use as soon as a problem substance could be identified. Over 800 references identified between 2001 and 2011, the authors have retained 65 relevant for their objective. This review shows that analgesics, opioid substitution drugs, and sedatives/hypnotics were the most widely represented, with significant geographical differences. Indeed, France and Germany were responsible for the greatest number of relevant references, respectively 15 and 9. The French data came mostly from the national addictovigilance system, ${ }^{[16-18]}$ using specific databases (observation of illicit psychotropic drugs or misuse from their drug use [observation des produits psychotropes illicites ou détournés de leur usage médicamenteux, OPPIDUM] survey $;^{[19,20]}$ studies on the health 
insurance databases, ${ }^{[21,22]}$ studies combining different data sources, ${ }^{[10,23]}$ studies on the French pharmacovigilance database). For Germany, studies were mostly done in the PharmaceuticalsMonitoring (Monitoring des Arzneimittelmisbrauchs bei Klienten Ambulanter Suchtberatungstellen [PHAR-MON]) database, a national registration system collecting data on drug use by outpatients seen in addiction specialized centres, ${ }^{[24]}$ or were studies performed in a single centre, on psychiatric populations, in emergency rooms or on toxicological data. Then, came the Scandinavian countries and the UK, with studies on pharmacovigilance databases, or drug-related death registries. ${ }^{[25]}$ For all other European countries, the number of references varied between 0 and 3 . According to the authors, this review provides information on drug abuse in Europe, but especially shows how the knowledge on the subject is fragmented due to the lack of relevant data: when the data exist, they are not accessible and/or unpublished; research on the topic is indigent; there are no multinational European approach in this particular area, although some experiments have been conducted in recent years. ${ }^{[26]}$

\section{Why a pharmacoepidemiological approach is needed? Pregabalin as an example}

Each year the EMCCDA publishes a report on European trends in substance abuse. ${ }^{[9,27]}$ This report is based on information provided by Member States, and includes signals identified by the EWS. Thus, in the last report on the year 2013, the EWS reported 81 new psychoactive substances. A growing number of these new drugs has legitimate use as medicines. Sometimes they are sold as medicines, in other cases they are sold clandestinely as illicit drugs such as heroin, or they may be sold as "legal highs", "research chemicals", and even as "food supplements". Recent examples, all reportedly injected by opioid users include: pregabalin (indicated for neuropathic pain, epilepsy and generalized anxiety disorder), tropicamide (parasympatholytic drug used as a mydriatic) ${ }^{[28]}$ and carfentanil (veterinary opioid). These medicines may be sourced in a number of ways: licensed medicines can be diverted from the regulated market and unlicensed medicines can be imported from outside the European Union. The first mention of pregabalin in EMCDDA reports is dating back to $2010 .{ }^{[9]}$ Pregabalin is a gabapentinoid substance (such as gabapentin), whose mechanism of action is not GABAergic directly, but decreases central neuronal excitability by binding to the auxiliary alpha-2-delta subunit of voltage-gated calcium channels. This leads to a decrease in the entry of calcium into the cell with a decrease of the release of certain neurotransmitters such as glutamate. The example of pregabalin will be used to illustrate the value of having pharmacoepidemiological tools in the particular field of drug abuse monitoring and addictovigilance in Europe. Since the first cases of abuse and dependence reported in the literature have appeared since 2006, from European countries (Italy, Germany, Turkey), ${ }^{[29-33]}$ we searched which European studies have explored this phenomenon. This searching was also completed by the recent review of Schifano on the potential for abuse of gabapentinoids. ${ }^{[34]}$

\subsection{Pharmacovigilance databases}

As the question of the possible abuse potential of pregabalin was discussed soon after its marketing, Schwan et al. conducted a specific analysis of drug abuse and dependence into the Swedish pharmacovigilance database (SWEDIS). ${ }^{[35]}$ The authors calculated an information component (IC), which is a logarithmic measure of association derived from a Bayesian data-mining algorithm used commonly in pharmacovigilance practice for the detection of potential safety signals. Out of 82714 reports in SWEDIS during the study period (1980-2009), a total of 198 reports indicative of abuse or addiction to any drug were identified, of which 16 concerned pregabalin. The first reports of abuse or addiction were received in the first quarter of 2008, and the IC became first significantly elevated in the fourth quarter of 2008 with four reports entered into SWEDIS. This first safety signal was confirmed by a complementary analysis into the WHO global ICSR database, VigiBase $^{\mathrm{TM}} \cdot{ }^{[36]}$ Using dependence-relatedness indicator on the whole database (including Europe and other countries), the authors showed that routine screening would have quantitatively highlighted a potential signal with pregabalin already in the second quarter. To the best of our knowledge, there are few examples of using VigiBase ${ }^{\mathrm{TM}}$ for identification of safety signals related to abuse or addiction, with the exception of methylphenidate as discussed by Micallef et al. ${ }^{[37]}$

In Germany, pregabalin was ranked as the $12^{\text {th }}$ most sold drug in Germany in 2009, with an increase in prescriptions of approximately $22 \%$ in 2009 compared to 2008 . Face to this indirect reference to a possible abuse of this drug, Gahr et al. analysed all reported cases of pregabalin abuse and dependence in Germany that had been submitted to the responsible federal authority, the German Federal Institute for Drugs and Medical Devices (Bundesinstitut für Arzneimittel und Medizinprodukte [BfArM]). ${ }^{[38]}$ A detailed assessment of the narratives of these reports revealed 55 reports $(3.5 \%$ of all pregabalin-adverse reactions, mainly men with a mean age of 36 years) that described abuse or dependence, with the first report dating back to April 2008 and the last dated August 2012. Despite the limitations of this study, it suggests an increasing frequency of pregabalin abuse or dependence in Germany, as observed previously in Sweden. ${ }^{[35]}$ According to the authors, pregabalin should be prescribed with great care to patients with drug abuse history, as long as robust assessments of factors that make patients susceptible for the development of pregabalinassociated addictive behaviours are missing.

By contrast, a study performed in the French pharmacovigilance database comparing the safety profile of pregabalin and gabapentin until the end of 2009 did not identify any signal or abuse or misuse for the 2 drugs. ${ }^{[39]}$ However, this study was done soon 
after pregabalin marketing in France. A study in the EudraVigilance database, investigating the characteristics of adverse drug reactions reported by patients from 2007 to 2011, has found that pregabalin was the most frequently involved in adverse reactions related to central nervous system drugs ( 1510 reports out of a total of 4766 reports related to central nervous systems drugs). ${ }^{[40]}$ The most frequently reported reaction was a lack of efficacy, and 14 reports concerned withdrawal syndrome. However, it is likely that patients who misuse or abuse pregabalin do not report this event as an adverse drug reaction, if they are not suffering of the morbid consequences of this abuse.

\subsection{Toxicology databases}

Each year, the EMCDDA receives from European Union members several indicators related to drug use. These indicators include the epidemiology of drug use, drug seizures, drug-related deaths and problematic drug use. However, this includes limited data on recreational drug toxicity as currently there is not a single robust source of information on the acute toxicity. Potential data sources can provide some information on the acute harm associated with drugs: user self-reports on Internet discussion forums; surveys of acute harm amongst users; fatal and non-fatal case reports and case series. This heterogeneity concerns both illicit substances and medicines. Concerning drug-related deaths, for example in France, data collected in the framework of DRAMES (relationship with death and drugs or substance abuse [décès en relation avec l'abus de médicaments et de substances]) do not cover all drug-related deaths in the country. ${ }^{[41]}$ By contrast, in Scandinavian countries such as Finland or Norway, toxicological analyses are recorded in a national exhaustive registry. ${ }^{[42,43]}$ Launiainen et al. found that pregabalin was identified as frequently as oxycodone in deaths occurring in young population (15-34 years), with two thirds of these deaths related with abuse. ${ }^{[42]}$ In Germany, pregabalin has been included in the systematic substances searching since October 2010. An analysis of toxicology results in Munich found that pregabalin positive cases increased from $2 \%$ of drug-related death in 2010 , to $6.7 \%$ the second year. ${ }^{[44]}$ Finally, a study investigating the serum levels of pregabalin in driving under the influence of drugs (DUID) cases in Finland, found pregabalin in more than $5 \%$ of the samples. Drivers were aged 20-40 years, were men (80\%) and pregabalin was most frequently identified with the concomitant use of benzodiazepines, cannabis, stimulants and opioids, and less frequently with alcohol and rarely with cocaine. ${ }^{[45]}$

\subsection{Studies among specific populations}

Results from the Psychonaut project, funded by the European Commission on the diffusion of new psychoactive substances on the Internet, were among the first published data on the potential for abuse of pregabalin in the "real-life". While the project was initially focused on new synthetic substances in Europe, Schifano et al. were interested in the use of recreational misuse of drugs as reported on various forums between 2008 and 2010, focusing their attention on pregabalin, gabapentin and clonazepam. ${ }^{[46]}$ Pregabalin was described as the "ideal psychotropic drug" for recreational use, reported as used mainly orally, but intravenous self-administration, rectal ("plugging"), and "parachute" (emptying the contents of a capsule into a bag) have also been reported. Pregabalin was reported as often taken in combination with other products in order to see the potential of psychogenic effects (alcohol, benzodiazepines, zopiclone and gabapentin). In addition, pregabalin use combined with cannabis, heroin, opioids, amphetamines, lysergic acid [LSD] and mephedrone were described. Users reported rapid tolerance, with intake above the maximum therapeutic doses $(600$ $\mathrm{mg}$ daily). Users also identified the need for a rapid and significant increase in the dose used because of the rapid tolerance. Despite the limitations of this study, the authors note that the increase in the number of mentions / discussions on a substance pleasant effects on web forums usually precedes an increase drug-related problems with this substance in the general population, as suggested by data from some European pharmacovigilance database.

In the UK, pregabalin appears more and more frequently as a "legal high" reported by users to induce a state similar to drunkenness, hence the street name "Budweiser's" ${ }^{[47]}$ A systematic review of all cases of patients with complications of recreational drug use and admitted to the emergency department at the Royal Victoria Hospital in Belfast from February 2012 to February 2013 identified 10 patients using pregabalin: six patients presented with seizures, and 2 patients required intubation and ventilation and were admitted to the intensive care unit. The authors emphasize the need for emergency physicians to be aware of the current use of pregabalin as a recreational drug and to be mindful of the potential of seizure activity.

Baird et al. performed a survey in six substance misuse clinics in Scotland between November 2011 and January 2012, using self-administered questionnaires. ${ }^{[48]}$ All patients attending the clinic over a 3-month period were asked to complete an anonymous questionnaire. Questions were asked about all drugs used, both prescribed and non-prescribed, with a special focus on gabapentinoids, gabapentin and pregabalin. Among the 129 respondents, $19 \%$ and $3 \%$ reported to using respectively gabapentin and pregabalin, and of these, $38 \%$ abused them in order to potentiate the "high" they obtained from methadone.

Pregabalin was detected in $12.1 \%$ of urine samples from 124 opiate-addicted subjects attending a German addiction clinic. ${ }^{[49]}$ None of these opiate-addicted patients were suffering from any of the indications for pregabalin prescribing, with most having confirmed that they had acquired pregabalin illicitly whilst being well aware that the molecule was not included in the standard drug monitoring system. By contrast, pregabalin was identified in the urines of 3 out the 111 other patients attending to the same 
centre for an addiction not related to opiates, but all used the drug for medical purpose (drug prescribed for neuropathic pain). These results underline the need to carefully prescribe this drug to opiatedependent patients.

\subsection{Surveys in general population: prescription databases or other studies}

According to Casati et al. ${ }^{[15]}$ prevalence studies using representative sample of the general population are very rare in Europe, making assessment of rates of abuse and dependence on medicines across European countries difficult. In large population-based surveys, such as ESPAD or HSBC, medicines are not named, and misuse is defined as the reporting of a "non-medical" use, i.e. drugs obtained without a prescription form. Moreover, these surveys focused on anxiolytic and hypnotic drugs, pregabalin being excluded from this definition because its use in pain, epilepsy or anxiety. Most of the authors of studies in pharmacovigilance databases reports a great increase of the pregabalin consumption in their country (+ $22 \%$ from 2008 to 2009 in Germany). ${ }^{[38]}$ Unfortunately, this is not easy to compare the patterns of consumption in all Europe, because these data are not easily accessible. We could obtain national consumption of pregabalin from sales or reimbursement data in 17 European countries, showing an important increase from 2006 (figure 1). For example, in Scandinavian countries, Germany and France, the level of use exceeds 2 DDD per thousand inhabitants per day in 2009. This level of consumption was contemporary of an increasing reporting of abuse and dependence cases in Sweden and Germany, whereas it was not observed in France.

Using the Norwegian prescription database (NorPD), Bramness et al. explored if the initiation of pregabalin reduced the consumption of benzodiazepines by investigating prescriptions given to individual patients, between 2004 and 2007. [50] According to these data, between $15 \%$ and $29 \%$ of the patients were able to stop using benzodiazepines after starting pregabalin and gabapentin respectively. Psychiatric patients who started pregabalin were able to reduce the amount of benzodiazepines by $48 \%$, compared to only $14 \%$ among starters of gabapentin. According to the authors, pregabalin might have a benzodiazepine sparing effect in patients with anxiety disorders. However, $20 \%$ of pregabalin starters initiated a benzodiazepine during the follow-up. Finally the main limitation of this study was to do not take account patterns of use, including abuse of pregabalin.

A cohort of pregabalin users was done using data linkage of 5 Swedish data sources: the Swedish Prescribed Drug Register, National Patient Register and the Cause of Death Register all held by the National Board of Health and Welfare, the regional primary care database of Stockholm County Council and information on patient education, income and country of birth. ${ }^{[51]}$ All patients who filled at least one prescription of pregabalin between July 2005 and
December 2009 were included, with a number of users in 2006 of 3400 and in 2009 of 11083 . Patients were mainly women $(63.1 \%)$, with a mean age of 54.8 years, the prevalence of treated patients being estimated at 5.6 subjects for 1000 inhabitants in 2009. According to the authors, pregabalin was mainly used as a second line drug, and a large proportion of patients only purchased one prescription and the persistence declined rapidly over time. However, only $40 \%$ of the patients were presented with the official indications, with a potential for off-label prescription. The authors report a great variability in daily dosage, but only mean doses are presented, which does not allow to identify abuse.

In order to estimate the prevalence of pregabalin misuse in the general population, a web survey was performed in UK, among a sample of 1500 people aged 16-59 years. ${ }^{[52]}$ Most of respondents were 20-40 years, and the self-reported lifetime prevalence of pregabalin misuse was $0.5 \%$, in contrast with an alleged lifetime prevalence of cocaine and cannabis use, respectively, of 8.1 and $28.1 \%$. Frequency of misuse of pregabalin (and/or gabapentin and baclofen which were also considered in this survey) was monthly in $37 \%$ of cases and between once per month and once per week in $50 \%$. The provenance of the majority of misuse appears to be from sources (street market and internet) other than legitimately prescribed medication, which has important implications for future strategies to reduce access to these medications.

The most recently published study was performed in Sweden, using the same data source than previously cited, ${ }^{[51]}$ with the aim of determining the characteristics of patients dispensed pregabalin that exceeds the maximum approved dose. ${ }^{[53]}$ Among the 48550 patients who were dispensed pregabalin at least three times during the study period, $8.5 \%$ had an estimated daily dosage that exceeded the maximum approved dose (i.e. over $600 \mathrm{mg}$ daily), with a previous drug misuse history having been identified in $31 \%$ of this specific subsample. This use was more likely in patients with a history and risk factors for addiction, which prompts the need for continued monitoring and surveillance for signals of abuse and for further assessment of the abuse potential of this drug.

\section{Conclusion}

This review reveals the difficulties to estimate and analyse patterns of medications abuse and misuse in Europe. Several pharmacoepidemiological data are existing, but they are not systematically available in all European countries. In the recent years, information exchange between EMCDDA and EMA through the early warning network allows to generate signals, for example with pregabalin. However, few data are available at the European level to confirm or not these signals, to estimate the prevalence of use, abuse and dependence, to identify risk factors for abuse or dependence and to estimate impact of this use in terms of morbidity and mortality. 


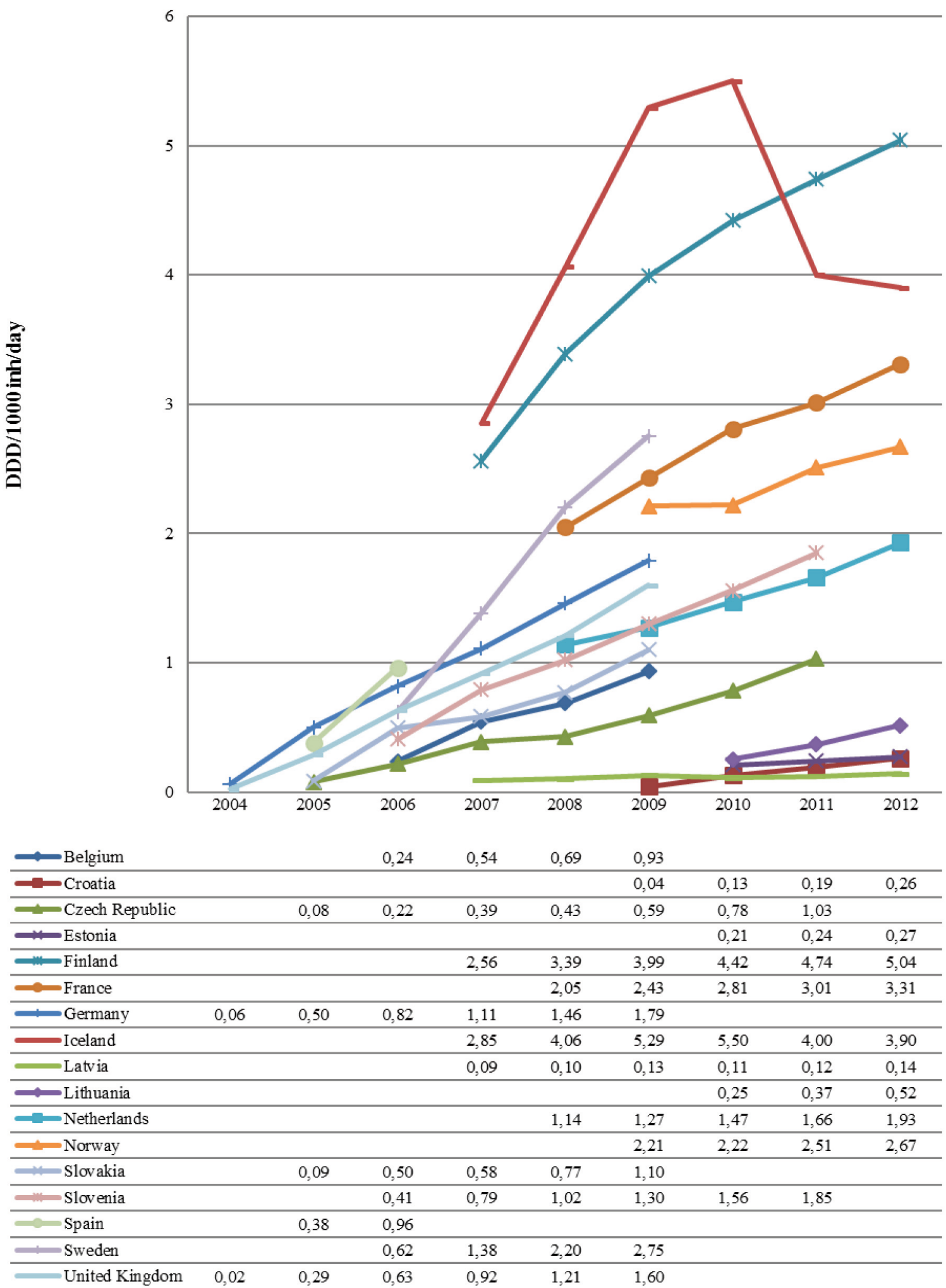

Fig. 1. Evolution of pregabalin consumption in Europe (2004-2012) estimated through national sales or reimbursement data, presented as number of defined daily doses (DDD) per thousand inhabitants and per day. 


\section{Conflicts of interests. None.}

Abbreviations. BfArM: German Federal Isntitute for Drugs and Medical Devices (Bundesinstitut für Arzneimittel und Medizinprodukte); DDD: defined daily dose; DUID: driving under the influence of drugs; ELDD: European Legal Database on Drugs; EMA: European Medicines Agency; EMCDDA: European Monitoring Centre for Drugs and Drug Addiction; ESPAD: European School Survey Project on Alcohol and Drugs; EWS: early warning system; HBSC: Health Behaviour In School Children; NorPD: Norwegian prescription database; OPPIDUM: observation of illicit psychotropic drugs of misuse from their drug use (observation des produits psychotropes illicites ou détournés de leur usage médicamenteux); SWEDIS: Swedish pharmacovigilance database; UMC: Uppsala Monitoring Centre; UNODC: United Nations Office on Drugs and Crime; WHO: World Health Organisation

\section{References}

1. Weisberg D, Stannard C. Lost in translation? Learning from the opioid epidemic in the USA. Anaesthesia 2013; 68: 1215-9

2. Hernandez SH, Nelson LS. Prescription drug abuse: insight into the epidemic. Clin Pharmacol Ther 2010; 88: 307-17

3. Davis JM, Severtson SG, Bucher-Bartelson B, et al. Using poison center exposure calls to predict prescription opioid abuse and misuse-related emergency department visits. Pharmacoepidemiol Drug Saf 2014; 23: 18-25

4. Cerda M, Ransome Y, Keyes KM, et al. Prescription opioid mortality trends in New York City, 1990-2006: examining the emergence of an epidemic. Drug Alcohol Depend 2013; 132: 53-62

5. Nordmann S, Frauger E, Pauly V, et al. Post-marketing surveillance systems for psychoactive prescription drug abuse. Therapie 2011; 66: 263-72

6. Pauly V, Frauger E, Pradel V, et al. Monitoring of benzodiazepine diversion using a multi-indicator approach. Int Clin Psychopharmacol 2011;26: 268-77

7. Lapeyre-Mestre M, Sapede C, Moore N, et al. Pharmacoepidemiology studies: what levels of evidence and how can they be reached? Therapie 2013; 68: $241-52$

8. OICS. Rapport annuel de l'Organe International de Contrôle des Stupéfiants 2013. Nations Unies; 2014

http://www.incb.org/documents/Publications/AnnualReports/AR2013/

French/AR_2013_F.pdf

Accessed January $12^{\text {th }}, 2015$ (132 pages)

9. OEDT. Annual report on the state of the drugs problem in Europe. In. Lisbon: EMCDDA; 2010

http://www.emcdda.europa.eu/publications/annual-report/2010 Accessed January $12^{\text {th }}, 2015$

10. Peyriere H, Eiden C, Micallef J, et al. Slow-release oral morphine sulfate abuse: results of the postmarketing surveillance systems for psychoactive prescription drug abuse in France. Eur Addict Res 2013;19: 235-44

11. Bramness JG, Henriksen B, Person O, et al. A bibliometric analysis of European versus USA research in the field of addiction. Research on alcohol, narcotics, prescription drug abuse, tobacco and steroids 2001-2011. Eur Addict Res 2014; 20: 16-22

12. European legal database on drugs http://www.emcdda.europa.eu/eldd Accessed January $12^{\text {th }}, 2015$

13. European database of suspected adverse drug reaction reports. http://www.adrreports.eu/ Accessed January $12^{\text {th }}, 2015$
14. Roussin A, Bouyssi A, Pouché L, et al. Misuse and dependence on non-prescription codeine analgesics or sedative H1 antihistamines by adults: a cross-sectional investigation in France. PLoS One 2013; 8: e76499

15. Casati A, Sedefov R, Pfeiffer-Gerschel T. Misuse of medicines in the European Union: a systematic review of the literature. Eur Addict Res 2012; 18: 228-45

16. Baumevieille M, Miremont G, Haramburu F, et al. The French system of evaluation of dependence: establishment in a legal system. Therapie 2001; 56: $15-22$

17. Micaleff J, Jolliet P, Victorri-Vigneau C, et al. First meeting of the French CEIP (Centres d'Evaluation et d'Information sur la Pharmacodépendance): Assessment of the abuse and pharmacodependence potential during drug development. Therapie 2008; 63: 55-65

18. Micallef-Roll J, Lapeyre-Mestre M. Second meeting of the French CEIP (Centres d'Évaluation et d'Information sur la Pharmacodépendance). Part I: how to evaluate and prevent the abuse and dependence on hypnotic/anxiolytic drugs? Therapie 2009; 64: 355-64

19. Moracchini C, Frauger E, Pauly V, et al. Harm reduction centers ("CAARUD"): privileged places for warning signal detection in addictovigilance. Therapie 2012; 67: 437-45

20. Frauger E, Moracchini C, Le Boisselier R, et al. OPPIDUM surveillance program: 20 years of information on drug abuse in France. Fundam Clin Pharmacol 2013; 27: 672-82

21. Pradel V, Delga C, Rouby F, et al. Assessment of abuse potential of benzodiazepines from a prescription database using "doctor shopping" as an indicator. CNS Drugs 2010; 24: 611-20

22. Micallef J, Pradel V, Thirion X, et al. Use of the health insurance database by the centres for evaluation and information on pharmacodependence: examples, interests and future prospects. Therapie 2004; 59: 581-8

23. Frauger E, Pauly V, Pradel V, et al. Evidence of clonazepam abuse liability: results of the tools developed by the French Centers for Evaluation and Information on Pharmacodependence (CEIP) network. Fundam Clin Pharmacol 2011; 25: 633-41

24. Casati A, Piontek D, Pfeiffer-Gerschel T. Patterns of non-compliant buprenorphine, levomethadone, and methadone use among opioid dependent persons in treatment. Subst Abuse Treat Prev Policy 2014; 9: 19

25. Giraudon I, Lowitz K, Dargan PI, et al. Prescription opioid abuse in the UK. Br J Clin Pharmacol 2013; 76: 823-4

26. Lapeyre-Mestre M, Gony M, Carvajal A, et al. A European Community Pharmacy-Based Survey to Investigate Patterns of Prescription Fraud through Identification of Falsified Prescriptions. Eur Addict Res 2014; 20: 174-82

27. EMCDDA publishes 2012 report on the state of the drugs problem in Europe. Euro Surveill 2012; 17 http://www.eurosurveillance.org/ViewArticle.aspx?Articleld=20315 Accessed January $12^{\text {th }}, 2015$

28. Bersani FS, Corazza O, Simonato P, et al. Drops of madness? Recreational misuse of tropicamide collyrium; early warning alerts from Russia and Italy. Gen Hosp Psychiatry 2013; 35: 571-3

29. Filipetto FA, Zipp CP, Coren JS. Potential for pregabalin abuse or diversion after past drug-seeking behavior. J Am Osteopath Assoc 2010; 110: 605-7

30. Grosshans M, Mutschler J, Hermann D, et al. Pregabalin abuse, dependence, and withdrawal: a case report. Am J Psychiatry 2010; 167: 869

31. Olaizola I, Ellger T, Young P, et al. Pregabalin-associated acute psychosis and epileptiform EEG-changes. Seizure 2006; 15: 208-10

32. Yargic I, Ozdemiroglu FA. Pregabalin abuse: a case report. Klinik Psikofarmakologi Bülteni 2011; 21: 64-66 DOI: 10.5350/KPB-BCP201121110

33. Gahr M, Franke B, Freudenmann RW, et al. Concerns about pregabalin: further experience with its potential of causing addictive behaviors. J Addict Med 2013; 7: 147-9

34. Schifano F. Misuse and abuse of pregabalin and gabapentin: cause for concern? CNS Drugs 2014; 28: 491-6 
35. Schwan S, Sundström A, Stjernberg E, et al. A signal for an abuse liability for pregabalin--results from the Swedish spontaneous adverse drug reaction reporting system. Eur J Clin Pharmacol 2010; 66: 947-53

36. Caster O, Edwards IR, Noren GN, et al. Earlier discovery of pregabalin's dependence potential might have been possible. Eur J Clin Pharmacol 2011; 67: 319-20

37. Micallef J, Frauger E, Palmaro A et al. Example of an investigation of an "emergent" phenomenon in addiction vigilance: the case of methylphenidate. Therapie 2015 DOI: 10.2515/therapie2015013

38. Gahr M, Freudenmann RW, Hiemke C, et al. Pregabalin abuse and dependence in Germany: results from a database query. Eur J Clin Pharmacol 2013; 69: 1335-42

39. Fuzier R, Serres I, Guitton E, et al. Adverse drug reactions to gabapentin and pregabalin: a review of the French pharmacovigilance database. Drug Saf 2013; 36: 55-62

40. Aagaard L, Hansen EH. Adverse drug reactions reported by consumers for nervous system medications in Europe 2007 to 2011. BMC Pharmacol Toxicol 2013; 14: 30

41. Glaizal M, Gazin V, Aymard I, et al. Suicidal poisonings with methadone in France: results of a two year national survey by the Toxicovigilance network. Clin Toxicol (Phila) 2012; 50: 841-6

42. Launiainen T, Broms U, Keskitalo-Vuokko K, et al. Nicotine, alcohol, and drug findings in young adults in a population-based postmortem database. Nicotine Tob Res 2011; 13: 763-71

43. Häkkinen M, Vuori E, Kalso E, et al. Profiles of pregabalin and gabapentin abuse by postmortem toxicology. Forensic Sci Int 2014; 241: 1-6

44. Lottner-Nau S, Övgüer B, Paul L, et al. Abuse of pregabalin-results of the post-mortem toxicology from 2010 to 2012. Toxichem Krimtech 2013; 80(special issue): $339-42$ https://www.gtfch.org/cms/images/stories/media/tk/tk80_4/LottnerNauEtAl.pdf

Accessed January $12^{\text {th }}, 2015$ (4 pages)
45. Kriikku P, Wilhelm L, Rintatalo J, et al. Pregabalin serum levels in apprehended drivers. Forensic Sci Int 2014; 243: 112-6

46. Schifano F, D'Offizi S, Piccione M, et al. Is there a recreational misuse potential for pregabalin? Analysis of anecdotal online reports in comparison with related gabapentin and clonazepam data. Psychother Psychosom 2011; 80: 118-22

47. Millar J, Sadasivan S, Weatherup N, et al. Lyrica nights-recreational pregabalin abuse in an urban emergency department. Emerg Med J 2013; 30: 874 DOI: 10.1136/emermed-2013-203113.20

48. Baird CR, Fox P, Colvin LA. Gabapentinoid abuse in order to potentiate the effect of methadone: a survey among substance misusers. Eur Addict Res 2014; 20: 115-8

49. Grosshans M, Lemenager T, Vollmert C, et al. Pregabalin abuse among opiate addicted patients. Eur J Clin Pharmacol 2013; 69: 2021-5

50. Bramness JG, Sandvik P, Engeland A, et al. Does Pregabalin (Lyrica $\left({ }^{\circledR}\right)$ ) help patients reduce their use of benzodiazepines? A comparison with gabapentin using the Norwegian Prescription Database. Basic Clin Pharmacol Toxicol 2010; 107: 883-6

51. Wettermark B, Brandt L, Kieler H, et al. Pregabalin is increasingly prescribed for neuropathic pain, generalised anxiety disorder and epilepsy but many patients discontinue treatment. Int J Clin Pract 2014; 68: 104-10

52. Kapil V, Green JL, Le Lait MC, et al. Misuse of the gamma-aminobutyric acid analogues baclofen, gabapentin and pregabalin in the UK. Br J Clin Pharmacol 2014; 78: 190-1

53. Boden R, Wettermark B, Brandt L, et al. Factors associated with pregabalin dispensing at higher than the approved maximum dose. Eur J Clin Pharmacol 2014; 70: 197-204

Correspondence and offprints: Maryse Lapeyre-Mestre, Service de Pharmacologie Médicale et Clinique, Faculte de Médecine, 37 Allées Jules Guesde, 31000 Toulouse France

E-mail: maryse.lapeyre-mestre@univ-tlse3.fr 